\title{
Memories of the past contribute to prevention: photography as a direct means for public understanding of science
}

\author{
Caterina Piccione
}

Istituto Nazionale di Geofisica e Vulcanologia, Rome, Italy

\author{
Article history \\ Received December 21, 2011; accepted January 26, 2012. \\ Subject classification: \\ Memories, Prevention, Historical images.
}

\begin{abstract}
There are thousands of ways to achieve a sustainable future for our Planet. Some of these follow high-value scientific research activities, while others simply aim to increase people's awareness of what can and should be done to improve our, and our children's, quality of life. The easiest way to develop this specific kind of 'spread of culture' consists of bringing back to life what was preserved of the history of a population and of a territory, by representing it in a renewed form, and by making it 'food for thought'. The Istituto Nazionale di Geofisica e Vulcanologia (INGV) followed this approach and decided to publish two volumes where the objective was to make people more aware of the geological and volcanic risks in some specific areas of Italy. The immediacy of the photography is used to tell the stories of volcanoes and earthquakes, to represent past events that have become 'memories'. and to use these as a basis to build a better future. Terremoto Calabro Messinese, 1908/2008 and Terre di Fuoco are the two photographic books that have been published by INGV in cooperation with Alinari, the oldest firm in the world in the field of photography and image communication. The photographs selected to be included in the two books had a double significance: on the one side, they had to convey to the reader the immediacy of the emotions that other people had felt and lived; and on the other side, they had to make people understand the importance of prevention. The fascination of history, the importance of memories of the past, and the extraordinary strength of images help the reader build a link between the past, the present and the future, where the lessons learnt from past centuries and from the study of the Earth and its energy help us to understand which steps should be taken to achieve a 'sustainable' future.
\end{abstract}

\section{Introduction}

Volcanic eruptions and earthquakes have always accompanied man over the centuries. As manifestations, sometimes extreme, of the internal dynamics of our Planet, they have been the subject of stories and documents of extraordinary quality. Indeed, the numerous testimonies, as well as their historical and literary value, represent an immense heritage for scientific research, and it is also thanks to these texts that we can reconstruct the history of the Earth, and in particular, the history of its volcanoes and earthquakes.

Man has always tried to describe what happens during an earthquake and to document the power of volcanic eruptions, their effects, the tragedies of the victims and survivors, the difficulties of reconstruction, and all of the steps of these natural events, almost wanting to leave a constructive witness of what they have observed.

While this applies to our entire Planet, in Italy, the immense archives of writings and testimonies of the past have allowed scholars to understand the series of volcanic eruptions and earthquakes over the centuries. This is information that is of vital importance for Italy, whose territory is characterized by areas of high seismic risk, and by the presence of numerous active volcanoes. Due to this great availability of material, the work of researchers, however, has had to cope with the need to achieve scientific reconstruction of events, while in the tales of past memories, technical data and timely observations have very often become mixed with partial, inaccurate, and sometimes fanciful, reports.

Since antiquity, there have been reconstructions of extreme natural events that have generated many doubts, as well as other writings representing, in some ways, the basics of seismology and volcanology. However, it was with the advent of communication by images that the tales of disasters took on a central and objective role for the world of scientific research. Photographs have the ability not to modify what they represent: as it was not possible to manipulate photographs, those who saw them could draw a full, objective interpretation, which provided conclusive evidence of understanding about what they represented.

Vintage photographs become extraordinarily sharp tools in the hands of researchers, as precious testimonies of past events, where their analysis is fundamental to the 

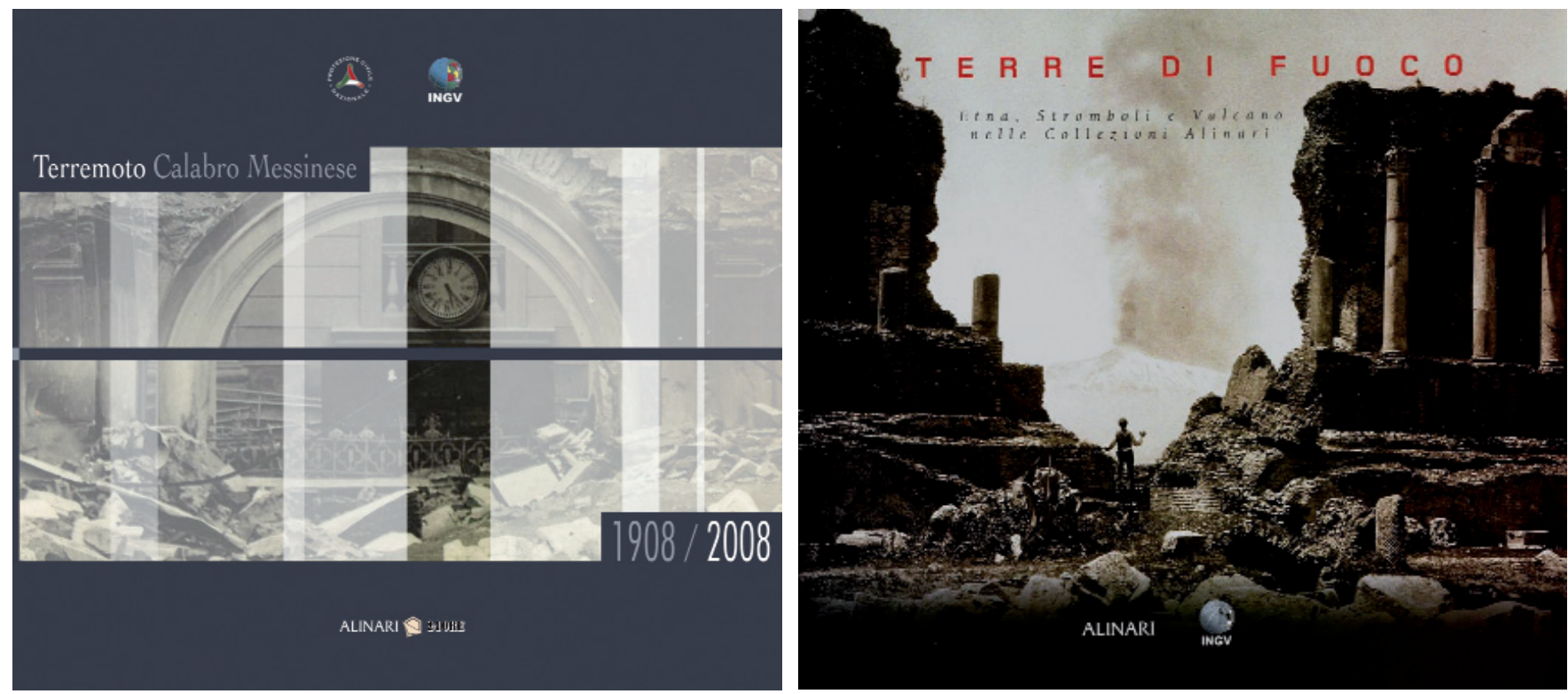

Figure 1. Left: Cover of Terremoto Calabro-Messinese 1908/2008. The clock of the Messina Central Post Office marks the time of the big shock: 5:21 am. Right: Cover of Terre di Fuoco. The explosive summit eruption of Etna seen from the Greek theater in Taormina (ca. 1880-1890), with the formation of an eruptive column.

understanding of the status quo and to the formulation of future scenarios. Indeed, photographs, as well as films, reduce, often to zero, the work of interpretation that researchers are called to play in the analysis. Due to the immediacy and accuracy of what pictures tell, the 'memory' becomes clear and translates into a suitable instrument for every use, from scientific to informative.

By looking at these photographs, every reader can find a source for reflection: from researchers, who find materials to improve their knowledge of a phenomena and their studies, to simple citizens, who have the ability to see the reality of the events that changed the history of some parts of their territory. This process is seen in the choice of the Istituto Nazionale di Geofisica e Vulcanologia (INGV; Italian National Institute of Geophysics and Volcanology) to publish two volumes that through their vintage photographs tell the story of the Sicilian volcanoes and the tragedy of the earthquake that devastated the Messina and Reggio Calabria area 100 years ago. The objective of this work was the combination of the 'purity' of the published photographs and a technical interpretation that was aimed at providing an explanation of the elements that caused the disruption of the territory that are still visible nowadays.

Images of past events can transmit a number of lessons to future generations that would otherwise be impossible to learn, and that must be translated into 'facts' to improve the prevention activities needed to avoid the effects of an earthquake or a volcanic eruption. Only with images can the culture of prevention reach the largest possible audience and the part of the population that is threatened by seismic or volcanic risk, thus increasing their awareness. Due to these 'memories', the world of research can provide useful information to guide future choice and to orient this towards full sustainability of the relationships between man and the surrounding environment, transforming even the simple vision of a photograph or a film into a prevention activity.

\section{Terremoto Calabro Messinese 1908/2008: the Calabria} and Messina earthquake, 1908/2008: a lesson to be learnt

The images collected by the researchers of the INGV in the book Terremoto Calabro Messinese 1908/2008 (The Calabria and Messina earthquake 1908/2008) communicate a sentiment that is at the same time one of bewilderment and hope. With surprise, some photographs document how portions of Reggio Calabria and Messina were almost untouched by the earthquake output, and even some miraculously intact buildings amidst the complete collapse of others. Thus, as well as being a depiction of the ruins, the photographs allow us to see beyond and to realize that buildings and houses have different damage types depending on the construction techniques.

The images themselves suggest that instead of talking about a miracle, we should perhaps speak of a wiser choice of the areas in which it is possible to build, or of a more conscious design of the seismic characteristics of the area of the Straits of Messina and Reggio Calabria, or simply of using better building materials. These demonstrate that there is a better way to build, and therefore this is a way that buildings should be constructed in areas where seismic risk is high.

The photographic gallery uses over a hundred shots to focus on three fundamental moments of the seismic phenomenon in relation to the life of man: the effects of the devastation on buildings and the environmental upheaval caused by the tsunami; the rescue process and life 
in the camps; and finally the return to normality. The survivors, rescuers and refugees are the protagonists of the sad rite that lasted for many weeks and that invariably recurs after each strong earthquake. It is not trivial to tell what happened over 100 years ago in the two cities bordering the Straits through vintage images, the tragic reminders that evoke a sense of profound loss. In the case of 1908, however, each frame appears to emerge from a sense of order, of almost quiet composure against an event of extraordinary power, where all, Italians and foreigners alike, worked together with a twofold aim: to save lives and to restore normality. Finally, in the images with the camps, the tension that arose from the torment of the tragedy is no more visible: the scenes of rebuilding ordered villages and wooden houses with pitched roof are very different from the images of the uncompassionate iron encampments of Belice and of Irpinia. The initiatives of solidarity and the presence of the most diverse categories of rescuers highlight at the same time the poverty of means combined with the absence of strategies, and the aim to do what was possible that united the actions of the institutions and the spontaneous actions of civil society.

As always happens in the case of large earthquakes, the seismic phenomenon surpasses its physical
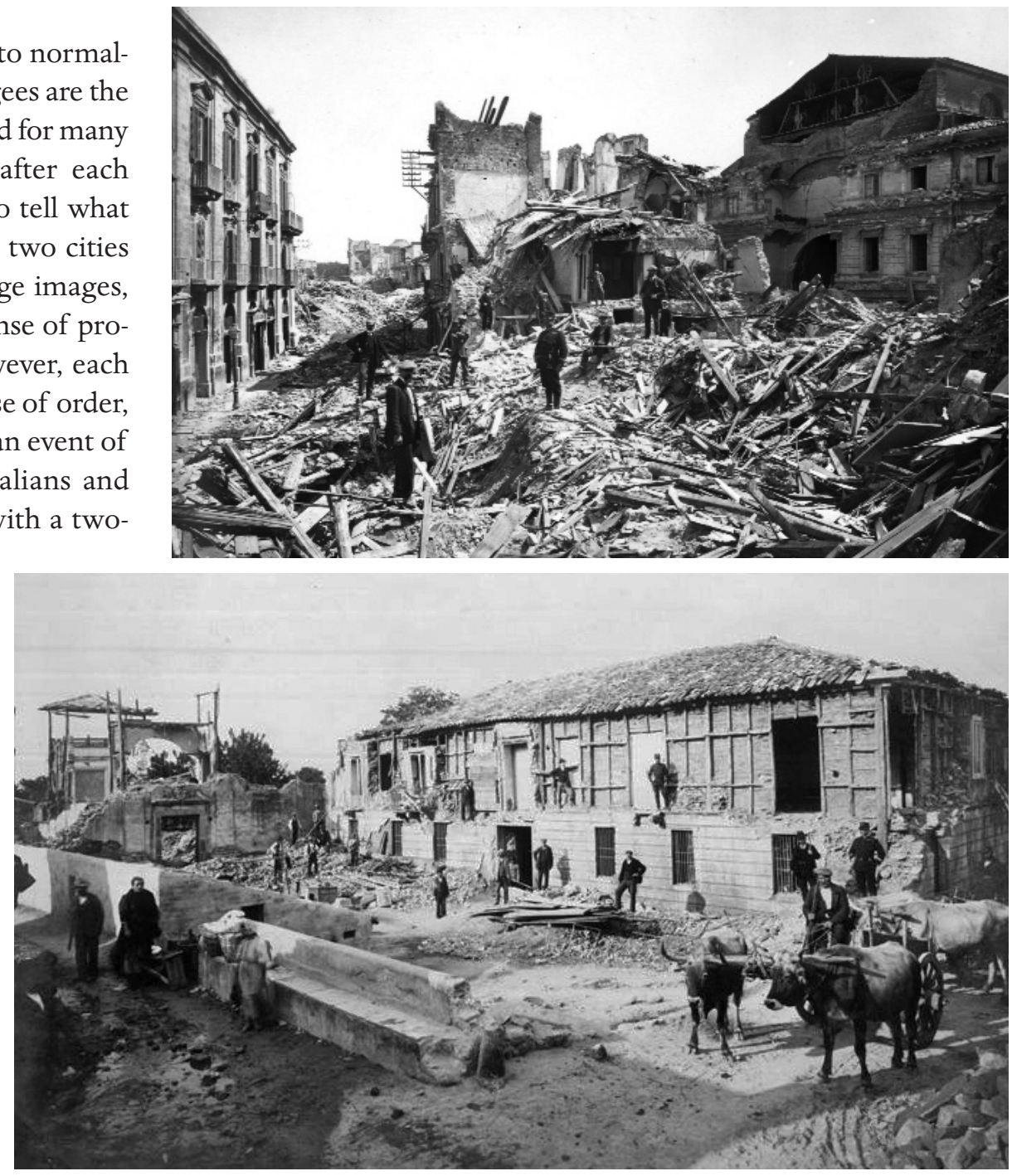

Figure 2 (top). Messina. The back of the Vittorio Emanuele Theater in Corso Cavour. The most significant damage was caused by the collapse of the surrounding buildings. A large opening just below the roof shows the complicated stage machinery that makes the theater appear to be more a factory or a mill. Figure 3 (bottom). Campo Calabro. A casa baraccata (hut, or shack) built following the antiseismic code enforced by the Bourbon administration after the large 1783 Calabrian earthquakes. The building that was supported by a wooden frame tightly connected to the masonry walls suffered minor damage. nature and becomes as well a so-

cial, cultural and administrative phenomenon, an event of great historical impact, the moral and material signs of which remain with the territory for several decades. The earthquake of 1908 also marked a major turning point for the whole of Italy as a country also from a scientific point of view, with the introduction of seismic classification and the related technical standards for buildings in more and more areas of the national territory. Giuseppe Mercalli was the first to draw up a list of places categorized by intensity grades using his macroseismic intensity scale, to which he added on this tragic occasion, grade 11: catastrophe. Consequently, Messina and Reggio Calabria became the symbols of experimentation into seismic prevention, and at the end of 1909 the country had the greatest number of seismographs in the world: this was when instrumental seismology was born.
Today, over 100 years later, the dense network of seismic monitoring of the INGV in Italy can locate the epicenter of an earthquake within a few minutes, even if it is of very low magnitude, and will understand in real-time the possible effects in that area. The continuous progress of scientific research allows us to update the seismic hazard maps of our territory with increasing accuracy.

\section{Terre di Fuoco: Lands of Fire: the Sicilian volcanoes narrated through images}

Within its educational activities, the INGV published the book Terre di Fuoco (Lands of Fire), a collection of photographs of Sicilian volcanoes. The material used by the INGV researchers came from the archives of the Alinari of Florence and from the Luce Institute, and it covers the period between the last decades of the 19th century and the 


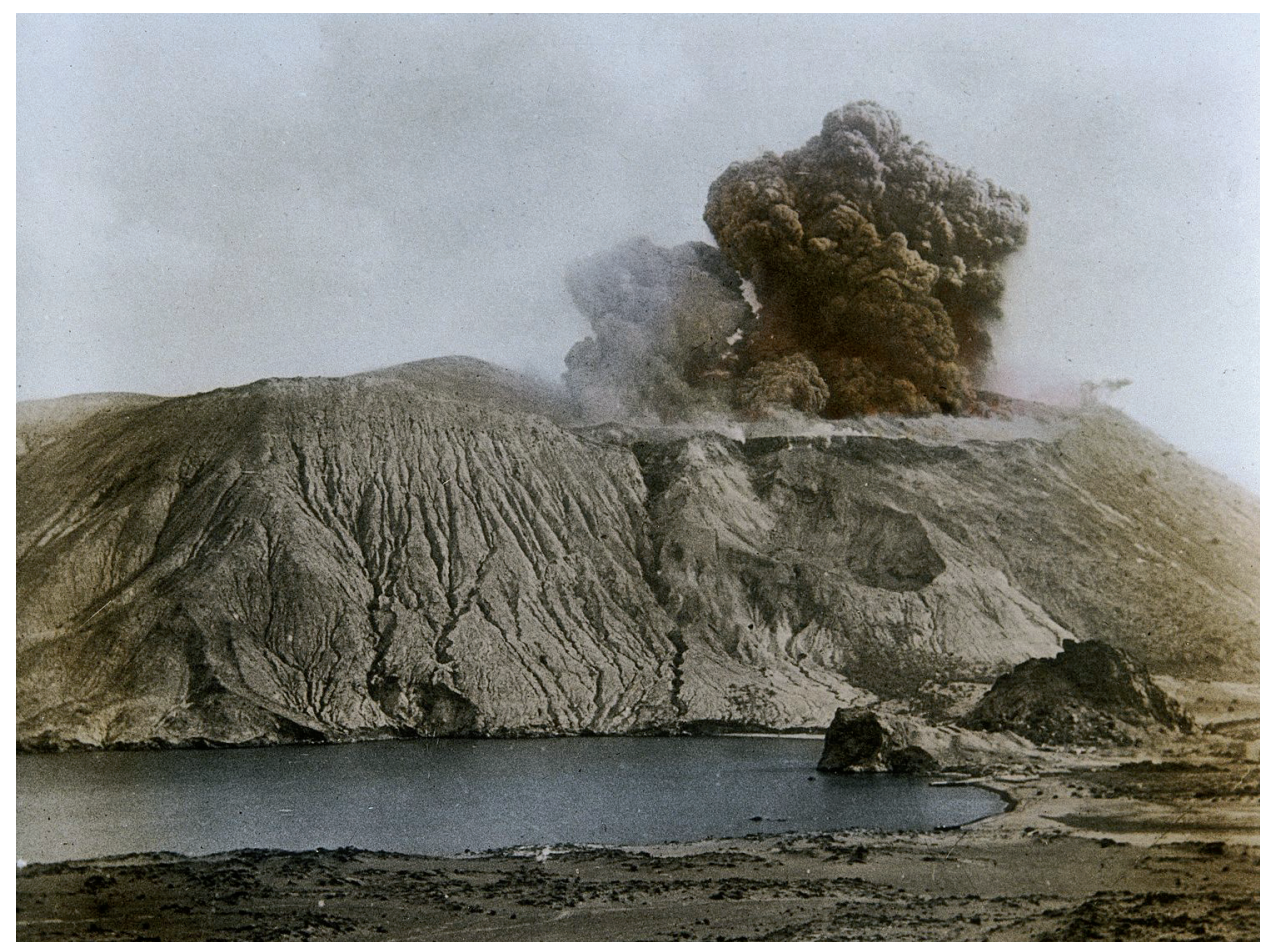

Figure 4. The Island of Vulcano. The eruption of 1888-1890. November 23, 1888. The initial phase of the explosion, known as Vulcanian, from the active cone of La Fossa was described later by Giuseppe Mercalli.

In Terre di Fuoco, the images are arranged according to a path through time and space, from which the profound changes to the territory emerge, both related to the activities of the volcanoes and to the activities of man. The documentation of some eruptions is very important; some date back to over a century ago and show some specific stages of the eruptive activity and their effects on the territory. Pictures tell us how all the areas at risk close to Etna and to the islands of Stromboli and Vulcano were previously sparsely populated, and the same pictures also make us understand what the energies of these volcanoes were like at that time, and how they are still today, and what effects a volcanic

first half of the 20th century. Etna, Vulcano and Stromboli are the protagonists of this volume, and they are chronicled through images that transmit intact to the reader the power of Sicilian volcanoes. The selected images guide the reader along a path of knowledge of the episodes and places that have always represented a theater where the stories of volcanic and human events are woven into an unbreakable combination that results in the memories, a tool of scientific knowledge and prevention that is essential for the development of a sustainable future, even in the areas exposed to severe risk, as that represented by active volcanoes.

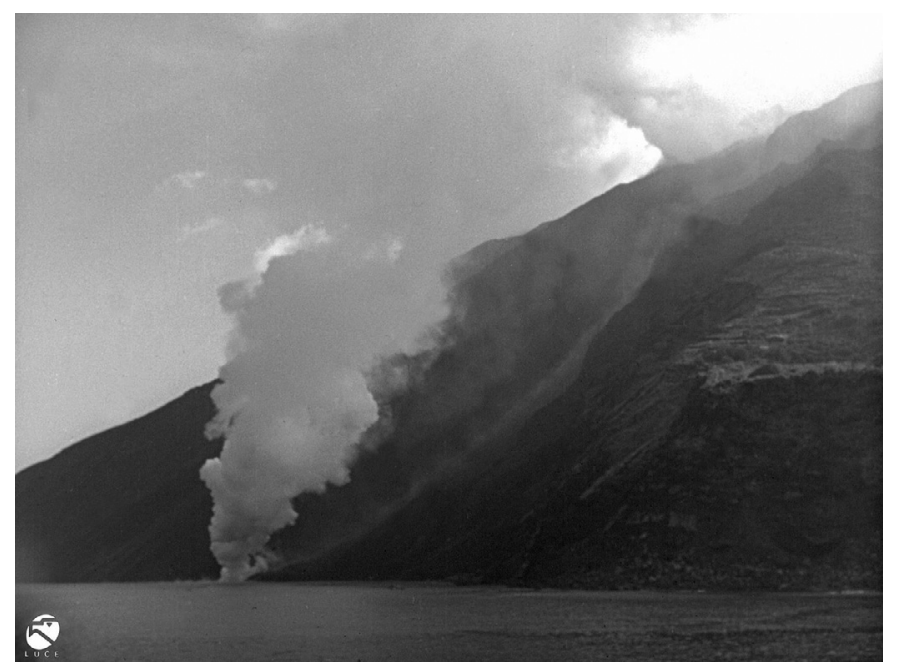

eruption can have on humans. Indeed, all of the photographs show the human condition before the overwhelming force of nature. They also show the dynamics that are not too different from those we saw in newspapers during the eruptions of Etna and Stromboli in recent years. If photographs, in their beauty, capture the readers' attention, the captions provide technical and scientific analysis that is capable of making anyone fully understand the activity of these volcanoes.

During the history of volcanology, the most important periods were often concurrent with major volcanic eruptions, which stimulated the growth of the scientific

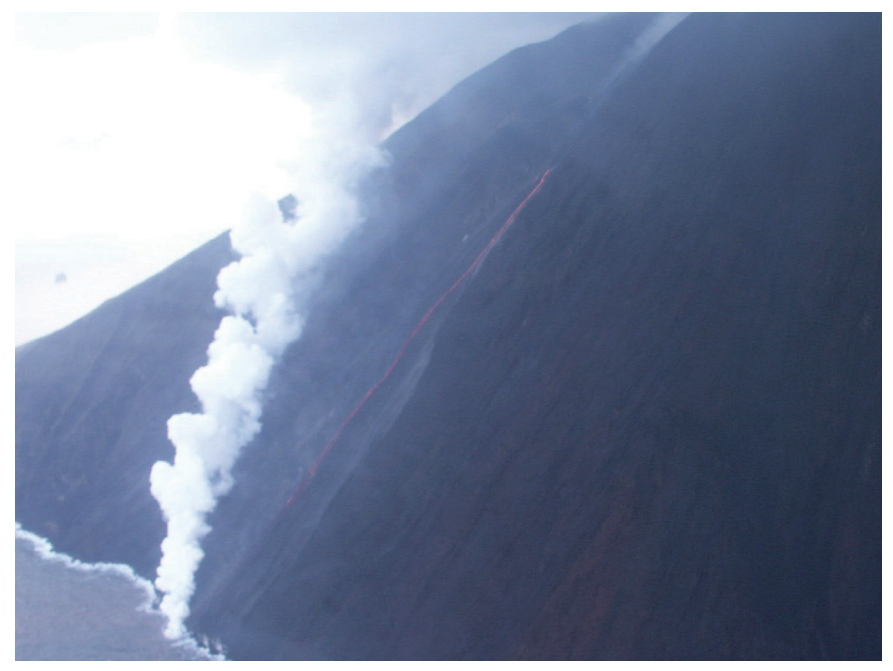

Figure 5. The Island of Stromboli. Left: Paroxysm of October 20, 1950. The eruptive activity continued with an impressive lava flow from the craters running along the slope of the Sciara del Fuoco, until it reached the sea. Right: Paroxysm of December 28, 2002. A photograph of January 19,2003 , with the lava flow reaching the sea. 
community. This was seen in the structure of the Etna Observatory, which was built in 1879 near the crater of Etna, at $2942 \mathrm{~m}$ a.s.1., as a center for astronomical observation. After a large eruption, the Etna Observatory was completed with a volcanology section dedicated to the observation and monitoring of the volcano. In 1926, the Observatory became part of the Department of Volcanology of the University of Catania, and in 1933, it became part of the Istituto Vulcanologico (Volcanology Institute) that was set up within this University. The Istituto Vulcanologico was a modern organization for the systematic monitoring of active Sicilian volcanoes (Etna, Stromboli and Vulcano), the activities of which were based on scientific criteria that are still valid today. It also led to the creation of the INGV in 1999.

\section{Conclusions}

The INGV decided to communicate using images and to bring back to life the memories of the past, by updating them and referring them to its patrimony of knowledge. This knowledge is the result of decades of research in the seismology and volcanology fields, in order to provide a prevention tool for the populations that live in areas at risk of earthquakes and volcanic eruptions.

With the effects that they have on the life and property of man, volcanoes and earthquakes have characterized the history of mankind, and more particularly, the of Italy. Knowing the past, acquiring its memory, analyzing and updating it to make it available to the community - this is what has helped to develop our scientific knowledge up to the current awareness. This development was also due to historical photographs of earthquakes and eruptions, which remain very important from the scientific point of view.

The charm of history, the importance of memories, and the extraordinary force of the historical photographs published by the INGV help the reader to create a strict link between the past, the present and the future. The power of images combined with the scientific analysis of earthquakes and volcanic eruptions offer an important contribution to the decisions to be taken to plan a sustainable future for those areas that are exposed to seismic or volcanic risk.

\section{References}

Azzaro, R., C. Piccione and G. Valensise (2008). Terremoto Calabro Messinese 1908/2008, Firenze, Alinari 24 Ore.

Bertolaso, G., E. Boschi, E. Guidoboni and G. Valensise, eds. (2008). Il terremoto e il maremoto del 28 dicembre 1908: analisi sismologica, impatto, prospettive, Bologna, SGA.

Bonaccorso, A., S. Branca, P. Del Carlo and C. Piccione (2005). Terre di Fuoco. Etna, Stromboli, Vulcano nelle
Collezioni Alinari, Firenze: Alinari, Catania: INGV. Ieni, R., C. Piccione, R. Rasà, A. Tripodo and L. Villari (1999). Storia eruttiva dello Stromboli e fenomeni correlati dal 1558 al 1996, Laboratorio di Cartografia Numerica dell'Istituto di Scienze della Terra, Università di Messina, n. 19.

Nave, R., and C. Piccione (2006). Education and information as tool for risk mitigation: the Italian experience in Neapolitan area and the Aeolian visitors centres, Sicily, First European Conference on Earthquake Engineering and Seismology, (Geneva, Switzerland); available at http:/ /hdl.handle.net/2122/2165.
Corresponding author: Caterina Piccione, Istituto Nazionale di Geofisica e Vulcanologia, Rome, Italy; email: caterina.piccione@ingv.it.

(C) 2012 by the Istituto Nazionale di Geofisica e Vulcanologia. All rights reserved. 